\title{
Evaluation of Low Carbon Development of European Union Countries and Turkey Using Grey Relational Analysis
}

\author{
Orkun ALPTEKIN, Nesrin ALPTEKIN, Bilal SARAÇ
}

\begin{abstract}
Energy, especially fossil fuels, plays an important role in ensuring economic growth and improving people's quality of life. Carbon dioxide emissions produced by fossil fuels is regarded as one of the main factors of global climate change. Although there are different opinions towards the issue of global warming, international communities have made substantial efforts in reducing national and global carbon dioxide emissions. However, low carbon development has been advocated by many countries as a new development model. Low carbon development is defined as utilizing less carbon to promote economic growth in the future. In our age of the increasing importance of climate change, low carbon development is a new form of sustainable development. The ultimate aim of low carbon development is to achieve environmental, economic and social sustainable development. In this context, country comparisons obtained by evaluation of low carbon development indicators are important. In this study, low carbon development levels of European Union countries and Turkey were evaluated by Grey Relational Analysis, which is a multiple criteria decision-making approach.
\end{abstract}

Keywords: entropy; grey relational analysis; low carbon development

\section{INTRODUCTION}

Global warming has become one of the most fundamental issues of our time. According to Intergovernmental Panel on Climate Change (IPCC) the global warming has been increasing at an alarming pace in recent decades which is proved by scientific evidences [1]. According to the report released from IPCC, there is a $90 \%$ possibility that the increase in greenhouse gases emitted by the human's activities leads to global warming [2]. There has been a growing concern about global climate change especially resulting from energy-related carbon dioxide $\left(\mathrm{CO}_{2}\right)$ emissions. While the countries keep their economic growth, they have begun to search new development ways to effectively reduce $\mathrm{CO}_{2}$ emissions. One of these ways is Low Carbon Development (LCD) which has become a widely advocated one [3]. LCD is a new representation form of sustainable development in the era of climate change. In other words, it is an indispensable part of sustainable development. LCD is a form of development which aims to achieve a low carbon economy through a process of de-carbonization, while contributing to sustainable development and tackling climate change [4].

Although the concept of LCD was accepted in Rio in 1992, the first step towards the European Union (EU) was taken in 2008. For this reason, it can be considered that the LCD is a new concept, so there is currently no internationally common definition of it [5]. Different organizations and people define it in different manners. The view 'using less carbon for growth' expressed in DFID's White Paper (2009) appears to be a common feature in what is implied by LCD [6]. According to this definition, low carbon growth promotes the consumption of products with less carbon and derivatives for growth [7].

In this sense, it is understood that LCD is focused on green growth. For this reason, it can be thought that it is necessary to focus on the developed countries, which cause the global emissions to increase for LCD [8].

As a new concept, it is important how to evaluate the LCD levels. To further promote the LCD, identifying effective measures and getting valuable experiences are important tasks. Therefore, how to accurately measure and reasonably evaluate the LCD level is the focus of LCD [2].
Since LCD has received much attention worldwide, researchers and academicians have also attempted to evaluate performance of it and compare LCD levels of countries. In addition, studies have been conducted to support the identification of strategies for developed and developing countries, provinces and cities.

Phdungsilp [9] used the Long-Range Energy Alternatives Planning System (LEAP) model to simulate sixteen proposed scenarios for Bangkok's LCD from 2000 to 2025 in Thailand. It is found that the most significant way for energy savings was in the transport sector. Jia et. al. [10], evaluated LCD levels of 47 countries. They suggested that energy conservation and emission reduction policy should be fixed as a longtime development strategy for every country. Qu and Liu [2] used DPSIR model to quantify the LCD levels of eight cities and five provinces in China. They found that the urbanization level and energy consumption elasticity coefficient were the main factors affecting the LCD levels.

Quantifying of LCD levels of countries, cities or regions is still a developing study area. The aim of this paper is to evaluate LCD levels of EU countries and Turkey in years 1997, 2002, 2007 and 2012. In order to address the challenges of climate changes, the EU Council has endorsed greenhouse gas reduction, renewable energy and energy efficiency targets for 2030 [11]. This study was carried out in order to determine the position of Turkey, as a candidate country for EU, within the LCD levels of the EU countries.

\section{METHODOLOGY 2.1 Entropy Method}

The Entropy method, which is based on the objective judgments of the decision maker, states that the criterion depends on its own characteristics as well as on the subjective judgments of the decision maker.

Entropy is taken as a concept that the uncertainty within a system of knowledge that expresses the uncertainty which is a measure of probability. For information about an event, it is necessary to understand the uncertainties that have the event. In this regard, it is highly probable that the events they are known to contain 
no more information. On the contrary, events with a low probability of occurrence include more information. In this context, the concept of entropy is considered as a mathematical expression of the expected realization value of the different probabilities of an event. The concept of entropy, in terms of the theory of probability was defined as a measure of uncertainty in the information [12]. This concept proposed by Shannon [12] in 1948, then Wang and Lee [13] have developed a method for calculating the weights of criteria by using entropy method. Steps of Shannon's Entropy can be summarized as the following [14].

Step 1: Regulation of evaluating matrix

In rows of the evaluation matrix to calculate the desired evaluation index alternatives, while columns in the evaluation criteria that will be used in the evaluation of alternative (criteria) is located. Accordingly, decision matrix $\boldsymbol{D}$ is shown as follows:

$$
\boldsymbol{D}=\left[\begin{array}{cccc}
a_{11} & a_{12} & \ldots & a_{1 n} \\
a_{21} & a_{22} & \ldots & a_{2 n} \\
\vdots & \vdots & \ddots & \vdots \\
a_{m 1} & a_{m 2} & \ldots & a_{m n}
\end{array}\right]_{m \times n}
$$

In the evaluation matrix with $m$ the number of alternatives, with $n$ is the number of evaluation criteria are shown.

Step 2: Normalization of the evaluating matrix

As criteria values in the evaluation matrix $\boldsymbol{D}$ are different from each other, the units of normalization are applied. The values of alternatives in order to normalize the following formulas are used, with regard to costs and benefits component.

According to the component of benefit to normalize as,

$r_{i j}=\frac{x_{i j}-\min \left(x_{i j}\right)}{\max \left(x_{i j}\right)-\min \left(x_{i j}\right)}$

while the component of cost to normalize, there are

$$
r_{i j}=\frac{\max \left(x_{i j}\right)-x_{i j}}{\max \left(x_{i j}\right)-\min \left(x_{i j}\right)}
$$

Thus, the normalized evaluation matrix can be shown as follows.

$$
\boldsymbol{R}=\left[\begin{array}{cccc}
r_{11} & r_{12} & \ldots & r_{1 n} \\
r_{21} & r_{22} & \ldots & r_{2 n} \\
\vdots & \vdots & \ddots & \vdots \\
r_{m 1} & r_{m 2} & \ldots & r_{m n}
\end{array}\right]_{m \times n}
$$

Step 3: Calculation of entropy values of all indexes

The value of $f_{i j}$ is computed via normalized decision matrix $\boldsymbol{R}$ as shown below:

$$
f_{i j}=\frac{r_{i j}}{\sum_{i=1}^{m} r_{i j}}, i=1,2, \ldots, m, j=1,2, \ldots, n
$$

Then entropy value of the index $\mathrm{j}$ is calculated.

$e_{i j}=-\frac{\sum_{i=1}^{m} f_{i j} \ln \left(f_{i j}\right)}{\ln (m)}, i=1,2, \ldots, m, j=1,2, \ldots, n$

where $\ln$ represents the natural logarithm and the coefficient $-1 / \ln (\mathrm{m})$ assures $0 \leq e_{j} \leq 1$. The entropy value of the index $j$ reaches maximum as $e_{j}=1$ in case the values of $f_{i j}$ are the same.

Step 4: Calculating the entropy weights of indexes The entropy weights of index $j$ are computed by using obtained entropy values as indicated below:

$$
w_{j}=\frac{1-e_{j}}{n-\sum_{i=1}^{m} e_{j}}, \sum_{j=1}^{n} w_{j}=1, j=1,2, \ldots, n
$$

According to Eq. (7) entropy weights show the importance level of useful information. Thus criteria having bigger entropy weights are considered as more important.

\subsection{Grey Relational Analysis}

Grey Relational Analysis (GRA) is a rating, classifying, ranking and decision making method based on the degree of influences between factors $[15,16]$. It can be used for making selection between alternatives in cases where a number of criteria exist [17]. Additionally, it is preferable for grouping variables where sample size is small and there is not any information about sampling distribution. The degree of influence between criteria is named as grey relational degree. Differences between GRA and other MCDM methods arise from the usage of reference series. According to the reference series maximum, minimum or ideal values of relevant criterion can be considered [18]. Steps of GRA can be summarized as follows:

Step 1: Arranging data set and constructing decision matrix

$m$ factor series are determined for making comparison.

$x_{i}=\left(x_{i}(j), \ldots, x_{i}(n)\right), i=1,2, \ldots, m, j=1,2, \ldots, n$

According to Eq. (8) alternatives are represented by $x_{i}$ and values of them with regard to each criterion are shown by $x_{i}(j)$. After obtaining $\mathrm{m}$ factor series decision matrix $\boldsymbol{X}$ is constructed as indicated below:

$$
\boldsymbol{X}=\left[\begin{array}{cccc}
x_{1}(1) & x_{1}(2) & \ldots & x_{1}(n) \\
x_{2}(1) & x_{2}(2) & \ldots & x_{2}(n) \\
\vdots & \vdots & \ddots & \vdots \\
x_{m}(1) & x_{m}(2) & \ldots & x_{m}(n)
\end{array}\right]_{m \times n}
$$

Decision matrix consists of $m$ alternatives and $n$ criteria.

Step 2: Constructing reference series and comparison matrix

Reference serial used for making comparison between the factors of decision problem is shown as follows: 
$x_{0}=x_{0}(j), j=1,2, \ldots, n$

Reference serial can be determined in two ways with respect to GRA method. According to the first step there exists reference serial generated for possible values of ideal alternative under each criterion and factor series are ranked based on distances from reference serial. For the second step the most ideal values of criteria are used by handling specifications of each criteria. Reference serial is added to the first row of decision matrix with the purpose of constructing comparison matrix [19]. In this study second step is preferred for determining reference serial.

Step 3: Constructing normalization matrix

Normalization process is required to make comparison between the series of data sets in cases where unit differentiation and wide range distribution exist. The concept of grey relational generation is used for this process in grey theory. Normalization is implemented by considering the effect of serial on objective function [20]. This affect can occur in three ways namely benefit cost and optimal condition.

Benefit condition: If higher serial values positive affect the objective function normalization is implemented according to Eq. (11):

$$
x_{i}^{*}=\frac{x_{i}(j)-\min _{j} x_{i}(j)}{\max _{j} x_{i}(j)-\min _{j} x_{i}(j)}
$$

Cost condition: If smaller serial values positive affect the objective function normalization is implemented according to Eq. (12):

$$
x_{i}^{*}=\frac{\max _{j} x_{i}(j)-x_{i}(j)}{\max _{j} x_{i}(j)-\min _{j} x_{i}(j)}
$$

Optimum condition: Serial values are normalized based on the determined optimal values as shown below:

$$
x_{i}^{*}=\frac{\left|x_{i}(j)-x_{0 b}(j)\right|}{\max _{j} x_{i}(j)-x_{0 b}(j)}
$$

According to Eq. (13) determined optimal value represented by $x_{0 b}(j)$ assures the condition of $\max x_{i}(j) \geq x_{0 b}(j) \geq \min x_{i}(j)$.

Thus decision matrix is transformed into normalization matrix $\boldsymbol{X}^{*}$ as indicated below:

$$
\boldsymbol{X}^{*}=\left[\begin{array}{cccc}
x_{1}^{*}(1) & x_{1}^{*}(2) & \ldots & x_{1}^{*}(n) \\
x_{2}^{*}(1) & x_{2}^{*}(2) & \ldots & x_{2}^{*}(n) \\
\vdots & \vdots & \ddots & \vdots \\
x_{m}^{*}(1) & x_{m}^{*}(2) & \ldots & x_{m}^{*}(n)
\end{array}\right]_{m \times n}
$$

Step 4: Establishing of absolute value table

Absolute differences between $x_{0}^{*}$ and $x_{i}^{*}$ are symbolized by $A_{0 i}(j)$ and calculated via Eq. (15):

$$
\Delta_{0 i}=\left|x_{0}^{*}(j)-x_{i}^{*}(j)\right|, i=1,2, \ldots, m, j=1,2, \ldots, n
$$

This form can be indicated as follows:

$$
\Delta_{0 i}=\left[\begin{array}{cccc}
\Delta_{01}(1) & \Delta_{01}(2) & \ldots & \Delta_{01}(n) \\
\Delta_{02}(1) & \Delta_{02}(2) & \ldots & \Delta_{02}(n) \\
\vdots & \vdots & \ddots & \vdots \\
\Delta_{0 m}(1) & \Delta_{0 m}(2) & \ldots & \Delta_{0 m}(n)
\end{array}\right]_{m \times n}
$$

Step 5: Generating grey relational coefficient matrix The elements of grey relational coefficient matrix are computed by using Eq. (17):

$\gamma_{0 i}(j)=\frac{\Delta_{\min }+\zeta \Delta_{\max }}{\Delta_{0 i}(j)+\zeta \Delta_{\max }}, i=1,2, \ldots, m, j=1,2, \ldots, n$

where $\Delta_{\max }=\max _{i} \max _{j} \Delta_{0 i}(j)$ and $\Delta_{\max }=\min _{i} \min _{j} \Delta_{0 i}(j)$.

In terms of Eq. (17) the separator coefficient is represented by $\zeta$ parameter and takes value between $[0,1]$ closed interval. Purpose of using this coefficient is to adjust the differences between $\Delta_{0 i}$ and $\Delta_{\max }$. Grey relational degree order thus does not change for each possible $\zeta$ value. It can be seen that separator coefficient $\zeta$ is generally considered as 0.5 in recent studies.

Step 6: Calculating grey relational degrees

Grey relational degree which is a measure of geometrical similarity between $x_{i}^{*}$ factor serial and $x_{0}^{*}$ reference serial in a grey system provides serial comparison. Size of grey relational degree reflects the relational power between $x_{i}^{*}$ factor serial and $x_{0}^{*}$ reference serial. Comprised series are same in cases where grey relational degree equals one. In other words similarity degree between factor and reference series can be obtained via grey relational degree [21].

Grey relational degrees are calculated in two ways. Firstly in cases where criteria having the equal importance levels grey relational degrees are computed by using Eq. (18).

$\Gamma_{0 i}=\frac{1}{n} \sum_{j=1}^{n} \gamma_{0 i}(j), i=1,2, \ldots, m$

In terms of Eq. (18) grey relational degree of $i^{\text {th }}$ serial is shown by $\Gamma_{0 i}$. Secondly in cases where criteria have different importance levels. Grey relational degrees are computed by using Eq. (19).

$\Gamma_{0 i}=\sum_{j=1}^{n}\left[w_{i}(j) \gamma_{0 i}(j)\right], i=1,2, \ldots, m$

Within the context of Eq. (19) importance level of $j^{\text {th }}$ criterion can be symbolized by $w_{i}(j)$. 


\section{DATA AND ANALYSIS}

In this study, 28 EU countries and Turkey were selected and nine low carbon development indicators were used. These indicators are: $\mathrm{CO}_{2}$ emissions $(\mathrm{C} 1), \mathrm{CO}_{2}$ emissions per capita (C2), energy intensity (C3), carbon intensity (C4), percentage of fossil fuel energy consumption (C5), percentage of renewable energy consumption (C6), percentage of forest area (C7), urbanization rate (C8) and human development index (C9).

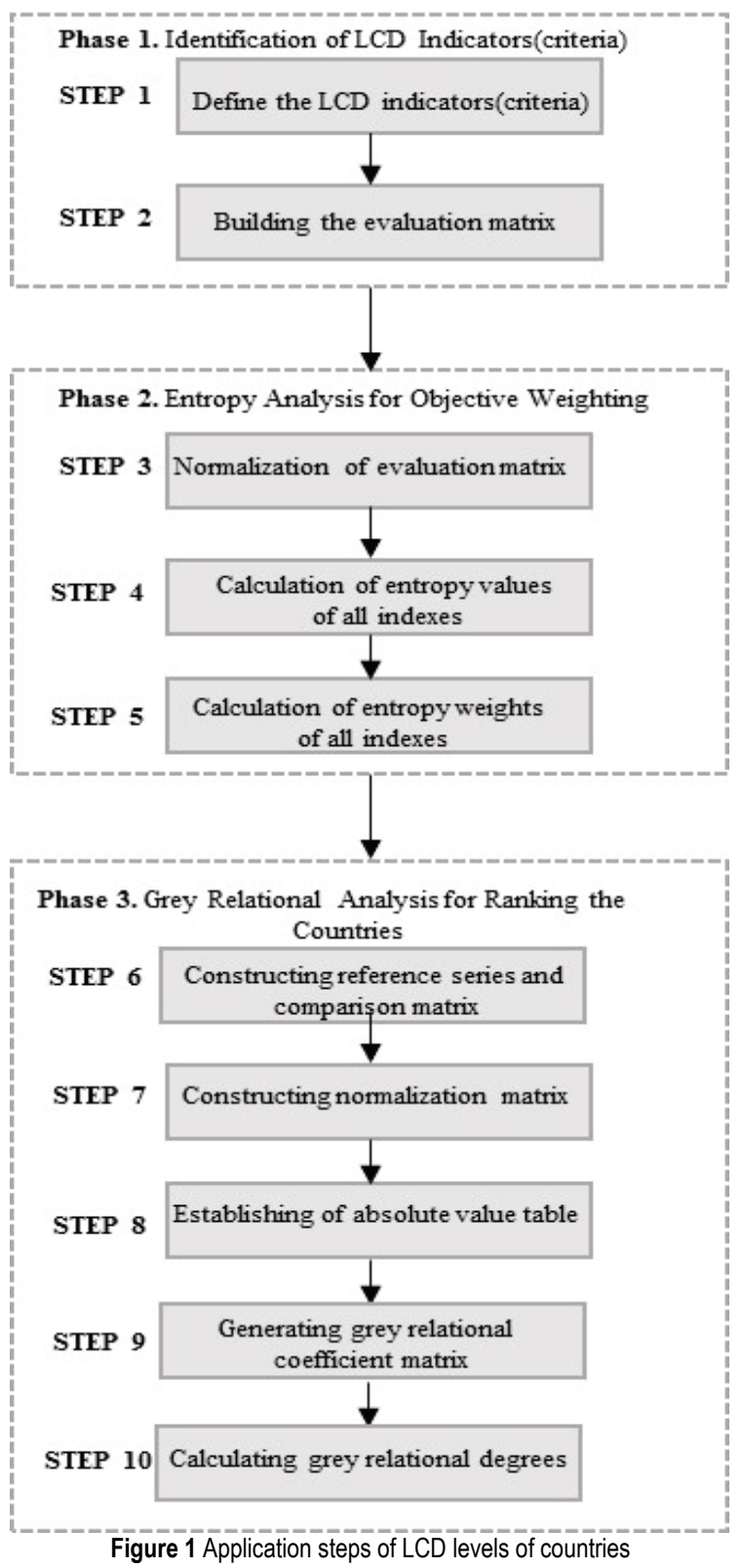

Data on $\mathrm{CO}_{2}$ emissions are coming from The Global Carbon Atlas. The unit of $\mathrm{CO}_{2}$ emissions is million tons of carbon dioxide. Data on $\mathrm{CO}_{2}$ emissions per capita, $\mathrm{CO}_{2}$ intensity, energy intensity, percentage of renewable energy consumption, percentage of fossil fuel energy consumption, percentage of forest area and urbanization level are coming from the World Development Indicators (WDI) of the World Bank database. Data on the human development index (HDI) are coming from the statistical database of the United Nations Development Programme.
$\mathrm{CO}_{2}$ emissions indicator is referred to as regional carbon data arising from both human activities and natural processes. The second indicator is the amount per capita of $\mathrm{CO}_{2}$ emissions. Energy intensity indicator shows how much energy is used to produce one unit of economic output. Carbon intensity is used to carbon dioxide amount per unit of economic output. Generally, the higher one of these four indicator is, the lower the regional LCD level is.

Percentage of fossil fuel energy consumption is the share of energy obtained from coal, oil, petroleum and natural gas products. The bigger indicator is, the lower the regional LCD level is.

Percentage of renewable energy consumption is the share of renewable energy in total energy consumption. It is a good indicator of carbon source's control level and usually the higher the percentage of renewable energy consumption is, the higher the regional LCD level is.

Percentage of forest area was used as an indicator of carbon dioxide absorption capacity. Usually, the bigger the percentage of forest area of a country is, the higher the LCD level of this country is.

Urbanization rate refers to the population shift from the village to the city. The bigger the urbanization rate of a certain country is, the higher the country's LCD level can be supposed to be [10].

The HDI was created to emphasize that people and their capabilities should be the ultimate criteria for assessing the development of a country, not economic growth alone [10].

In this study, Human Development Index (HDI) is used to measure as an integrated indicator of a certain country' development in education, health and income per capita. High level of HDI in a country results in people having higher education quality, healthier body and higher economic conditions.

The bigger the HDI of a certain country is, the higher the country's LCD level can be supposed to be [10].

Some of these criteria have a negative effect on LCD level. This means that the regional LCD level is reducing when the corresponding indicator's value is increasing. These indicators are considered cost criteria.

The indicators having positive effects on LCD level means that the LCD level is increasing with the indicator's value increasing. These indicators are considered benefit criteria. The relationships of all these indicators with LCD level are shown in Tab. 1.

Table 1 Relationships of indicators with LCD level

\begin{tabular}{|l|c|}
\hline \multicolumn{1}{|c|}{ LCD Indicators } & Benefit/Cost \\
\hline $\mathrm{CO}_{2}$ emissions (C1) & Cost \\
\hline $\mathrm{CO}_{2}$ emissions per capita (C2) & Cost \\
\hline Energy intensity (C3) & Cost \\
\hline Carbon intensity (C4) & Cost \\
\hline Percentage of fossil fuel energy consumption (C5) & Cost \\
\hline Percentage of renewable energy consumption (C6) & Benefit \\
\hline Percentage of forest area (C7) & Benefit \\
\hline Urbanization rate (C8) & Benefit \\
\hline Human development index (C9) & Benefit \\
\hline
\end{tabular}

The application steps of LCD levels of countries are demonstrated in Fig. 1. It can be seen that the application steps of countries' LCD levels is an integrated process of the two methods: Entropy method and grey relational analysis. First step is to select LCD indicators/criteria. After building evaluation matrix of countries' LCD 
indicator values, then indicators' weights of the LCD level can be calculated by Entropy method. Then grey relational degrees are calculated for ranking countries' LCD levels.

\subsection{Weights of LCD Indicators(Criteria)}

In a multicriteria decision making, the weights attributed to the various criteria represent the importance of each criterion in the evaluation procedure and directly make effects on the ranking order of alternatives. Determining how to assign weights to the criteria is a very important part of this methodology. Indeed an arbitrary assignment of weights can highly influence the result of the analysis. In the literature, the methods for finding the weights are grouped into two classes: subjective and objective weights. The subjective methods, such as AHP (Analytic Hierarchy Process) and Delphi method, include the methods that determine the weights exclusively according to the judgements of the decision makers. The subjective choices of decision makers are based on their own knowledge and perception of the problem analyzed.

Table 2 Entropy value calculations for criteria C1 in year 1997

\begin{tabular}{|l|r|r|r|r|r|}
\hline Countries & $\mathrm{C} 1(1997)$ & $r_{i j}$ & $f_{i j}$ & $\ln \left(f_{i j}\right)$ & $e_{i j}$ \\
\hline Austria & 67.163 & 0.930 & 0.038 & -3.271 & -0.124 \\
\hline Belgium & 122.723 & 0.869 & 0.035 & -3.338 & -0.119 \\
\hline Bulgaria & 55.626 & 0.942 & 0.038 & -3.258 & -0.125 \\
\hline Croatia & 18.939 & 0.982 & 0.040 & -3.216 & -0.129 \\
\hline Cyprus & 6.222 & 0.996 & 0.041 & -3.202 & -0.130 \\
\hline Czech Rep. & 129.713 & 0.862 & 0.035 & -3.347 & -0.118 \\
\hline Denmark & 65.590 & 0.931 & 0.038 & -3.269 & -0.124 \\
\hline Estonia & 18.254 & 0.983 & 0.040 & -3.216 & -0.129 \\
\hline Finland & 62.355 & 0.935 & 0.038 & -3.266 & -0.125 \\
\hline France & 401.842 & 0.566 & 0.023 & -3.767 & -0.087 \\
\hline Germany & 923.080 & 0.000 & 0.000 & 0.000 & 0.000 \\
\hline Greece & 93.308 & 0.901 & 0.037 & -3.302 & -0.122 \\
\hline Hungary & 61.288 & 0.936 & 0.038 & -3.264 & -0.125 \\
\hline Ireland & 38.256 & 0.961 & 0.039 & -3.238 & -0.127 \\
\hline Italy & 442.372 & 0.522 & 0.021 & -3.848 & -0.082 \\
\hline Latvia & 8.595 & 0.993 & 0.041 & -3.205 & -0.130 \\
\hline Lithuania & 15.118 & 0.986 & 0.040 & -3.212 & -0.129 \\
\hline Luxemburg & 8.561 & 0.993 & 0.041 & -3.205 & -0.130 \\
\hline Malta & 2.255 & 1.000 & 0.041 & -3.198 & -0.131 \\
\hline Netherlands & 6.375 & 0.996 & 0.041 & -3.203 & -0.130 \\
\hline Poland & 365.460 & 0.606 & 0.025 & -3.700 & -0.092 \\
\hline Portugal & 54.579 & 0.943 & 0.039 & -3.257 & -0.125 \\
\hline Romania & 118.468 & 0.874 & 0.036 & -3.333 & -0.119 \\
\hline Slovakia & 44.190 & 0.954 & 0.039 & -3.245 & -0.126 \\
\hline Slovenia & 15.991 & 0.985 & 0.040 & -3.213 & -0.129 \\
\hline Spain & 263.304 & 0.717 & 0.029 & -3.531 & -0.103 \\
\hline Sweden & 57.629 & 0.940 & 0.038 & -3.260 & -0.125 \\
\hline United K. & 550.525 & 0.405 & 0.017 & -4.103 & -0.068 \\
\hline Turkey & 205.366 & 0.779 & 0.032 & -3.447 & -0.110 \\
\hline & & & & & \\
\hline
\end{tabular}

On the other hand, the objective methods, such as entropy method and multiple objective programming, are based on mathematical computation using the data, unlike decision maker's judgements. The entropy can accurately reflect the utility value of indicator's information to determine the weights. The weights obtained by entropy have higher reliability and accuracy than by a subjective weighting method [22].

In this study, entropy method is used to obtain weights of the criteria. For this purpose, firstly evaluating matrix which consists of LCD indicators ' of each country is constructed. Countries take part in the rows of the matrix while indicators take part in its columns. Microsoft Excel is used for all the calculations. Calculations of entropy value for criteria $C_{1}$ in year 1997 are given in Tab. 2 . Analyses of other years have been made in similar way. The original data of $\mathrm{C}_{1}$ for all countries are given in first column of Tab. 2. $\mathrm{C}_{1}$ are the cost criteria so, the data is normalized by Eq. (3). Normalized data is shown in second column in Tab. 2. $f_{i j}$ value of each indicator is calculated by using Eq. (5). Then entropy value $\left(e_{i j}\right)$ of each indicator is calculated by Eq. (6). Finally, entropy weight of each indicator is calculated by using Eq. (7).

All entropy weights of LCD indicators in analysed years are given in Tab. 3. The entropy weights of LCD indicators for analyzed years are shown in Fig. 2.

Table 3 Entropy values of LCD indicators in analysed years

\begin{tabular}{|c|c|c|c|c|}
\hline & 1997 & 2002 & 2007 & 2012 \\
\hline C1 & 0.033 & 0.035 & 0.042 & 0.042 \\
\hline C2 & 0.041 & 0.033 & 0.033 & 0.037 \\
\hline C3 & 0.128 & 0.143 & 0.149 & 0.134 \\
\hline C4 & 0.061 & 0.081 & 0.089 & 0.089 \\
\hline C5 & 0.187 & 0.188 & 0.19 & 0.177 \\
\hline C6 & 0.249 & 0.238 & 0.221 & 0.226 \\
\hline C7 & 0.103 & 0.101 & 0.107 & 0.115 \\
\hline C8 & 0.12 & 0.116 & 0.116 & 0.12 \\
\hline C9 & 0.078 & 0.065 & 0.053 & 0.059 \\
\hline
\end{tabular}

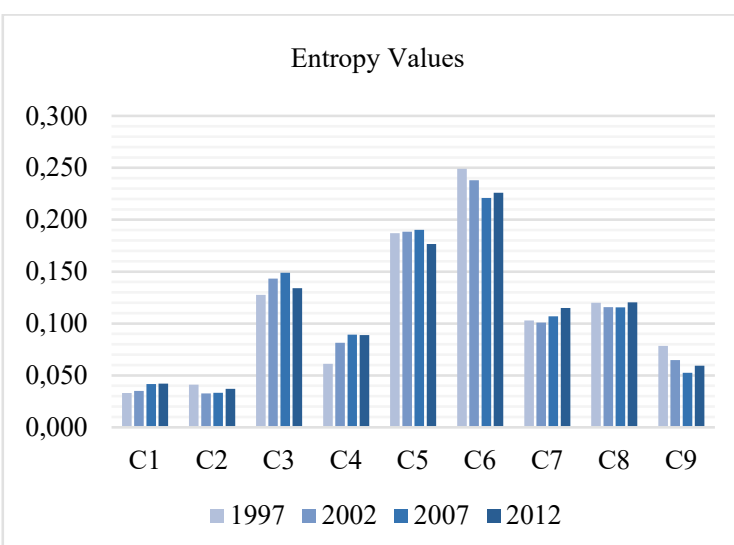

Figure 2 Entropy weights of criteria

According to the entropy method results in Fig. 2, the most important LCD indicator is the percentage of renewable energy consumption (C6) in all analysed years. The least important one is $\mathrm{CO}_{2}$ emissions $(\mathrm{C} 1)$ in year 1997, while $\mathrm{CO}_{2}$ emissions per capita (C2) is the least important indicator in years 2002, 2007 and 2012.

\subsection{Grey Relational Degrees}

In the grey relational analysis, reference series and comparison matrix were arranged for the LCD indicators of countries first. In the second step of GRA, reference serial is constructed. Calculations of grey relational degree for criteria C1 in year 1997 are given in Tab. 4. The original data of $\mathrm{C} 1$ for all countries are given in the first column of Tab.4. Reference serial is composed using Eq. (10) and reference value for criteria for the year 1997 is 2.255 . It is shown in the first row in the comparison matrix.

Then, comparison matrix was normalized using Eq. (11) and (12) for benefit condition and cost condition. Calculations for reference serial and $x_{1}^{*}$ (Austria) which is cost condition are shown below: 


$$
\begin{aligned}
& x_{1}^{*}(\text { reference })=\frac{923080-2255}{923080-2255}=1.000 \\
& x_{1}^{*}(\text { Austria })=\frac{923080-67163}{923080-2255}=0.930
\end{aligned}
$$

Absolute value is obtaned using Eq. (15). For Austria absolute value is calculated as $\Delta_{01}(1)=|1.000-0.930|=0.070$. The other absolute values of criterion $\mathrm{C} 1$ are shown in third column of Tab. 4.

Table 4 Grey Relational Analysis for Criteria C1 in year 1997

\begin{tabular}{|l|c|c|c|c|c|}
\hline \multicolumn{1}{|c|}{ Countries } & $\mathrm{C} 1$ & $x_{i}^{*}(1)$ & $\Delta_{0 i}(1)$ & $\gamma_{0 i}(1)$ & $\Gamma_{0 i}(1)$ \\
\hline Ref. Serial & $\mathbf{2 . 2 5 5}$ & $\mathbf{1 . 0 0 0}$ & & & \\
\hline Austria & 67.163 & 0.930 & 0.070 & 0.877 & 0.029 \\
\hline Belgium & 122.723 & 0.869 & 0.131 & 0.793 & 0.026 \\
\hline Bulgaria & 55.626 & 0.942 & 0.058 & 0.896 & 0.030 \\
\hline Croatia & 18.939 & 0.982 & 0.018 & 0.965 & 0.032 \\
\hline Cyprus & 6.222 & 0.996 & 0.004 & 0.991 & 0.033 \\
\hline Czech Rep. & 129.713 & 0.862 & 0.138 & 0.783 & 0.026 \\
\hline Denmark & 65.590 & 0.931 & 0.069 & 0.879 & 0.029 \\
\hline Estonia & 18.254 & 0.983 & 0.017 & 0.966 & 0.032 \\
\hline Finland & 62.355 & 0.935 & 0.065 & 0.885 & 0.029 \\
\hline France & 401.842 & 0.566 & 0.434 & 0.535 & 0.018 \\
\hline Germany & 923.080 & 0.000 & 1.000 & 0.333 & 0.011 \\
\hline Greece & 93.308 & 0.901 & 0.099 & 0.835 & 0.028 \\
\hline Hungary & 61.288 & 0.936 & 0.064 & 0.886 & 0.029 \\
\hline Ireland & 38.256 & 0.961 & 0.039 & 0.927 & 0.031 \\
\hline Italy & 442.372 & 0.522 & 0.478 & 0.511 & 0.017 \\
\hline Latvia & 8.595 & 0.993 & 0.007 & 0.986 & 0.033 \\
\hline Lithuania & 15.118 & 0.986 & 0.014 & 0.973 & 0.032 \\
\hline Luxemburg & 8.561 & 0.993 & 0.007 & 0.986 & 0.033 \\
\hline Malta & 2.255 & 1.000 & 0.000 & 1.000 & 0.033 \\
\hline Netherlands & 6.375 & 0.996 & 0.004 & 0.991 & 0.033 \\
\hline Poland & 365.460 & 0.606 & 0.394 & 0.559 & 0.019 \\
\hline Portugal & 54.579 & 0.943 & 0.057 & 0.898 & 0.030 \\
\hline Romania & 118.468 & 0.874 & 0.126 & 0.798 & 0.026 \\
\hline Slovakia & 44.190 & 0.954 & 0.046 & 0.917 & 0.030 \\
\hline Slovenia & 15.991 & 0.985 & 0.015 & 0.971 & 0.032 \\
\hline Spain & 263.304 & 0.717 & 0.283 & 0.638 & 0.021 \\
\hline Sweden & 57.629 & 0.940 & 0.060 & 0.893 & 0.030 \\
\hline United K. & 550.525 & 0.405 & 0.595 & 0.456 & 0.015 \\
\hline Turkey & 205.366 & 0.779 & 0.221 & 0.694 & 0.023 \\
\hline & & & & & \\
\hline
\end{tabular}

Later, grey relational coefficient matrix was generated. Grey relational coefficients are computed by using Eq. (17). In this equation, the values are determined as $\Delta_{\min }=0, \Delta_{\max }=1$ and $\zeta=0.5$. Grey relational coefficient for Austria is calculated as below:

$\gamma_{01}($ Austria $)=\frac{0+0.5 \cdot 1}{0.070+0.5 \cdot 1}=0.877$

The calculations for other countries are given in the fourth column in Tab. 4.

Finally in grey relational anaysis, grey relational degrees were calculated. Grey relational degree displays the similarity between the normalized decision matrix and the standard series. Similarity increases as the grey relational degree increases. The highest similarity gives the best alternative in the multicriteria decision making problem [23]. In case of having equal importance level of criteria, grey relational degrees were calculated by using Eq. (18), otherwise Eq. (19) was used. The grey relational degree of each country for the years analyzed is given in Tab. 5.

Table 5 Grey Relational Degrees of Countries

\begin{tabular}{|l|c|c|c|c|}
\hline \multicolumn{1}{|c|}{ Countries } & 1997 & 2002 & 2007 & 2012 \\
\hline Sweden (SWE) & $0.870(\mathbf{1})$ & $0.856(\mathbf{1})$ & $0.870(\mathbf{1})$ & $0.846(\mathbf{1})$ \\
\hline Finland (FIN) & $0.691(\mathbf{2})$ & $0.689(\mathbf{2})$ & $0.662(\mathbf{2})$ & $0.686(\mathbf{2})$ \\
\hline Latvia (LVA) & $0.633(\mathbf{3})$ & $0.665(\mathbf{3})$ & $0.615(\mathbf{3})$ & $0.612(\mathbf{3})$ \\
\hline Estonia (EST) & $0.589(4)$ & $0.593(\mathbf{4})$ & $0.583(\mathbf{4})$ & $0.579(\mathbf{4 )}$ \\
\hline Austria (AUT) & $0.582(\mathbf{5})$ & $0.574(\mathbf{5})$ & $0.566(\mathbf{5})$ & $0.573(\mathbf{5})$ \\
\hline France (FRA) & $0.580(6)$ & $0.572(6)$ & $0.561(6)$ & $0.563(7)$ \\
\hline Belgium (BEL) & $0.558(7)$ & $0.555(8)$ & $0.547(7)$ & $0.556(8)$ \\
\hline Portugal (PRT) & $0.547(8)$ & $0.504(11)$ & $0.513(11)$ & $0.518(12)$ \\
\hline Lithuania (LTU) & $0.518(9)$ & $0.566(7)$ & $0.548(8)$ & $0.525(10)$ \\
\hline Spain (ESP) & $0.514(10)$ & $0.496(14)$ & $0.538(9)$ & $0.516(13)$ \\
\hline Luxemburg (LUX) & $0.506(11)$ & $0.501(13)$ & $0.500(13)$ & $0.493(15)$ \\
\hline Slovenia (SVN) & $0.501(12)$ & $0.520(10)$ & $0.526(10)$ & $0.531(9)$ \\
\hline Denmark (DNK) & $0.501(13)$ & $0.520(9)$ & $0.538(9)$ & $0.567(6)$ \\
\hline Turkey (TUR) & $0.498(14)$ & $0.477(16)$ & $0.455(25)$ & $0.440(28)$ \\
\hline Croatia (HRV) & $0.498(15)$ & $0.472(17)$ & $0.471(20)$ & $0.486(17)$ \\
\hline Malta (MLT) & $0.491(16)$ & $0.503(12)$ & $0.502(12)$ & $0.523(11)$ \\
\hline Netherlands (NLD) & $0.486(17)$ & $0.486(15)$ & $0.496(14)$ & $0.505(14)$ \\
\hline Italy (ITA) & $0.478(18)$ & $0.470(18)$ & $0.466(22)$ & $0.479(21)$ \\
\hline United K. (GBR) & $0.476(19)$ & $0.468(19)$ & $0.458(24)$ & $0.465(24)$ \\
\hline Germany (GER) & $0.472(20)$ & $0.467(20)$ & $0.479(17)$ & $0.485(18)$ \\
\hline Greece (DEU) & $0.468(21)$ & $0.461(22)$ & $0.471(21)$ & $0.468(23)$ \\
\hline Cyprus (CYP) & $0.462(22)$ & $0.444(27)$ & $0.443(28)$ & $0.451(27)$ \\
\hline Ireland (IRL) & $0.456(23)$ & $0.460(23)$ & $0.486(16)$ & $0.485(19)$ \\
\hline Hungary (HUN) & $0.455(24)$ & $0.462(21)$ & $0.474(19)$ & $0.489(16)$ \\
\hline Romania (ROU) & $0.455(25)$ & $0.450(26)$ & $0.463(23)$ & $0.477(22)$ \\
\hline Slovakia (SVK) & $0.450(26)$ & $0.458(24)$ & $0.478(18)$ & $0.484(20)$ \\
\hline Bulgaria (BGR) & $0.438(27)$ & $0.458(25)$ & $0.448(26)$ & $0.463(25)$ \\
\hline Czech Rep. (CZE) & $0.434(28)$ & $0.433(28)$ & $0.447(27)$ & $0.456(26)$ \\
\hline Poland (POL) & $0.403(\mathbf{2 9})$ & $0.410(\mathbf{2 9})$ & $0.408(\mathbf{2 9})$ & $0.417(\mathbf{2 9})$ \\
\hline & & & & \\
\hline
\end{tabular}

As it can be seen from Tab. 5, first five countries that have the highest grey relational degree are Sweden, Finland, Latvia, Estonia and Austria in all analysed years. Poland has the lowest grey relational degree in these years. Turkey has been in the middle ranking for the first two years, but it has fallen in the last ranking for the last two years.

\subsection{Findings and Discussion}

It can be seen from Tab.5 that Sweden has always the highest value of LCD level and Poland has always the lowest value of LCD level in analysed years. Similarly, Finland, Latvia, Estonia and Austria have always values between 0.6 and 0.7 , and they are in the same order in country rankings. France, Belgium, Portugal, Lithuania,

Spain, Luxemburg, Slovenia and Denmark have gotten still values in between 0.5 and 0.6 , but their rankings are changed. Malta's value is only under 0.5 in year 1997, its value is increased over 0.5 in years 2002, 2007 and 2012. The rest of the countries' values are under 0.5 and higher than 0.4. But their rankings changed in different years.

In order to give clarity to the analysis, LCD levels of countries are distinguished in four groups. The LCD level of countries in the first group is under 0.5 and higher than 0.4 . The second group has the $0.5-0.6$ values of the LCD level and the third group consists of the countries that have 0.6-0.7 values of the LCD levels. Finally the fourth group only consists of Sweden which has the highest value of LCD level. The categorized map of different LCD levels of EU countries and Turkey is shown in Fig. 3. 


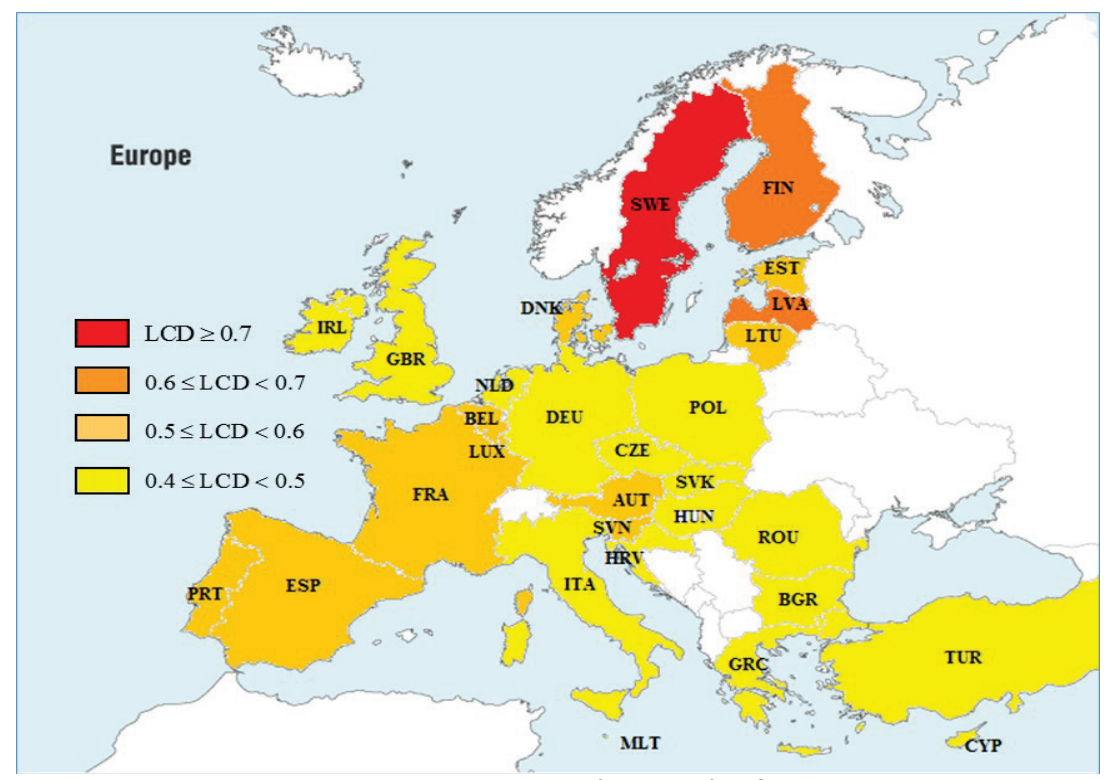

Figure 3 The categorized map of countries for LCD levels

Table 6 The original data of four countries

\begin{tabular}{|c|c|c|c|c|c|c|c|c|c|c|}
\hline Countries & Years & C1 & $\mathrm{C} 2$ & $\mathrm{C} 3$ & $\mathrm{C} 4$ & $\mathrm{C} 5$ & C6 & $\mathrm{C} 7$ & $\mathrm{C} 8$ & C9 \\
\hline \multirow{4}{*}{ Sweden } & 1997 & 57.62 & 5.90 & 1.034 & 7.73 & 35.64 & 35.62 & 68.56 & 83.94 & 0.93 \\
\hline & 2002 & 55.99 & 6.43 & 1.11 & 6.74 & 37.45 & 36.150 & 68.69 & 84.13 & 0.95 \\
\hline & 2007 & 52.02 & 5.25 & 0.96 & 5.45 & 32.45 & 42.93 & 68.63 & 84.59 & 0.91 \\
\hline & 2012 & 45.71 & 5.52 & 1.05 & 5.27 & 30.999 & 49.91 & 68.92 & 85.363 & 0.92 \\
\hline \multirow{4}{*}{ Finland } & 1997 & 62.36 & 11.66 & 1.86 & 9.11 & 53.27 & 28.97 & 73.13 & 81.47 & 0.92 \\
\hline & 2002 & 64.58 & 11.86 & 1.77 & 8.22 & 51.28 & 29.58 & 73.30 & 82.50 & 0.94 \\
\hline & 2007 & 66.24 & 12.10 & 1.74 & 7.23 & 49.82 & 32.09 & 72.92 & 83.17 & 0.89 \\
\hline & 2012 & 50.73 & 10.16 & 1.56 & 6.77 & 43.07 & 39.12 & 73.11 & 83.82 & 0.89 \\
\hline \multirow{4}{*}{ Poland } & 1997 & 365.46 & 9.04 & 3.42 & 8.95 & 95.90 & 5.98 & 29.40 & 61.58 & 0.81 \\
\hline & 2002 & 303.51 & 7.71 & 3.33 & 6.63 & 95.87 & 7.56 & 29.76 & 61.79 & 0.85 \\
\hline & 2007 & 331.56 & 5.77 & 2.40 & 3.80 & 79.24 & 23.15 & 35.79 & 58.75 & 0.81 \\
\hline & 2012 & 320.86 & 8.34 & 3.14 & 4.80 & 90.98 & 11.08 & 30.60 & 60.69 & 0.82 \\
\hline \multirow{4}{*}{ Turkey } & 1997 & 205.37 & 3.29 & 2.82 & 3.76 & 83.78 & 20.89 & 13.01 & 63.18 & 0.73 \\
\hline & 2002 & 218.19 & 3.16 & 2.77 & 3.75 & 86.09 & 17.49 & 13.48 & 65.95 & 0.75 \\
\hline & 2007 & 308.65 & 4.10 & 2.85 & 3.62 & 90.50 & 12.50 & 14.14 & 68.98 & 0.70 \\
\hline & 2012 & 357.50 & 4.38 & 2.86 & 3.65 & 89.34 & 12.84 & 14.82 & 71.83 & 0.72 \\
\hline
\end{tabular}

Note: The units of first eight indicators millions tons of carbon dioxide, million tons carbon dioxide per capita, million tonnes oil equivalent per billion dollars, million tons carbon dioxide per billion dollars, $\%, \%, \%$ and $\%$, respectively. The ninth indicator has no unit.

These four countries namely, Sweden, Finland, Poland and Turkey, should be analysed and discussed in more detail because the first two have the highest value and Poland has the lowest value. Turkey's value has also declined over the years. It was in the middle of the ranking of countries in the first two years (1997 and 2002), but its value has declined to bottoms of the ranking in the last two years (2007 and 2012).

In order to explain the reasons of the difference between these four countries, the original data of four countries is given in Tab. 6. It can be seen that the percentage of renewable energy consumption (C6) and percentage of forest area (C7) indicators of Sweden and Finland (first two countries) is evidently much higher than Poland and Turkey's one. Sweden and Finland use less fossil energy and more renewable energy than the latter two. This should be the first important cause of the difference.

It can be seen from Tab. 6 that forest coverage area of Sweden and Finland is much more than of Poland and Turkey. This should be the second important cause.

It can be found that the last two countries have evidently much more carbon dioxide emissions than the first two countries.
This may be another important reason of the difference between the countries. In addition, percentage of fossil fuel energy consumption of the last two countries is also much higher than of the first two countries.

In the light of the above findings, some suggestions can be made about the low carbon development strategies of these countries. First of all, carbon dioxide emission reduction policy should be adjusted for a long term development strategy for every country, especially for Turkey and Poland. Another suggestion is that the percentage of fossil energy consumption should be reduced as much as possible in some countries, such as Turkey and Poland. In addition, percentage of renewable energy consumption should be increased as soon as possible. Also, the percentage of forest area should be developed for some countries, especially in Turkey.

\section{CONCLUSION}

LCD has attracted attention from countries and researchers in recent years. LCD is a new concept in the literature so that there is still not a common definition of it. Generally speaking, LCD is a new path of economic development aiming at reducing carbon dioxide emissions and achieving sustainable development. 
In this study, it was aimed to determine the LCD levels of the countries. In the empirical analysis, 28 European Union countries and Turkey were chosen and 9 LCD indicators were selected as criteria.

Assessment of countries according to their LCD levels is a multiple criteria decision making problem. Multiple criteria decision making refers to making decisions in the presence of multiple, usually conflicting, criteria. In this paper, entropy method and grey relational analysis were used to determine LCD of countries. Firstly, entropy method was used to assign the weights of criteria. Entropy method is an objective weighting method which can be thought of as a measure of information content and it indicates how much can be learned from the data. Then the entropy values of criteria were used as importance weights in grey relational analysis.

According to the entropy method results, renewable energy consumption (C6) is found to be the most important LCD indicator with entropy values $0.249,0.238,0.221$ and 0.226 , respectively in analyzed years. In addition, the least important indicator is $\mathrm{CO}_{2}(\mathrm{Cl})$ emissions with entropy value 0.033 in year 1997 , and $\mathrm{CO}_{2}$ emissions per capita (C2) with entropy value 0.033 in years 2002 and 2007 and 0.037 in year 2012 .

According to the results of the grey relational analysis, Sweden has the highest low carbon development level in the European Union countries and Turkey with grey values $0.870,0.856,0.870$ and 0.846 , respectively in analyzed years, while Poland has the lowest grey values 0.403 , $0.410,0.408$ and 0.417 in analyzed years. Besides these, Turkey is in the middle rankings with grey values 0.498 and 0.477 for the first two years, but it has fallen in the last rankings with grey values 0.455 and 0.440 for the last two years.

Some essential suggestions are the following: Carbon dioxide emission reduction policy should be adjusted for a long term development strategy for every country, especially for Turkey and Poland. Another suggestion is that the percentage of fossil energy consumption should be reduced as much as possible in some countries, such as Turkey and Poland. In addition, percentage of renewable energy consumption should be increased as soon as possible. Also, the percentage of forest area should be developed for some countries, especially in Turkey.

For further research, other multiple criteria decision making methods can be used to evaluate LCD concept. In addition, other indicators may be used that are thought to influence LCD in the analysis.

\section{REFERENCES}

[1] Intergovernmental Panel on Climate Change. (2014). Climate change 2014: Synthesis report. http://www.ipcc.ch (05.06.2016)

[2] Qu, Y. \& Liu, Y. (2016). Evaluating the Low-Carbon Development of Urban China. Environment, Development and Sustainability, 1-15. https://doi.org/10.1007/s10668-016-9777-8

[3] Yuan, H., Zhou, P., \& Zhou, D. (2011). What is Low-Carbon Development? A Conceptual Analysis. Energy Procedia, 5, 1706-1712. https://doi.org/10.1016/j.egypro.2011.03.290

[4] Zhou, P. (2014). Low-Carbon Development. Encyclopedia of Quality of Life and Well-Being Research. 3723-3725. https://doi.org/10.1007/978-94-007-0753-5_3382

[5] Mulugetta, Y. \& Urban, F. (2010). Deliberating on low carbon development. Energy Policy, 38(12), 7546-7549. https://doi.org/10.1016/j.enpol.2010.05.049

[6] Study on Low Carbon Development and Green Employment in China. 2010. http://www.ilo.org/ wcmsp5/groups/public/---asia/---ro-bangkok/---ilobeijing/documents/publication/wcms_155390.pdf (11.18.2016)

[7] Urban, F. (2010). The MDGs and Beyond: Can Low Carbon Development be Pro-poor? IDS bulletin, 41(1), 92-99. https://doi.org/10.1111/j.1759-5436.2010.00109.x

[8] International Energy Agency. (2010). World Energy Outlook. OECD. http://www.Worldenergyoutlook.org /media/weo2010.pdf (16.01.2017).

[9] Phdungsilp, A. (2010). Integrated energy and carbon modelling with a decision support system: policy scenarios for low-carbon city development in Bangkok. Energy Policy, 38(9), 4808-4817. https://doi.org/10.1016/j.enpol.2009.10.026

[10] Jia, J., Fan, Y., \& Guo, X. (2012). The low carbon development (LCD) levels' evaluation of the world's 47 countries (areas) by combining the FAHP with the TOPSIS method. Expert Systems with Applications, 39, 6628-6640. https://doi.org/10.1016/j.eswa.2011.12.039

[11] European Union Policy on Energy. (2016). http://www.ab.gov.tr/index.php?p=80\&l=2 (03.01.2017)

[12] Shannon, C. E. (1948). Mathematical theory of communication. The Bell System Technical Journal, 27, 379-423. https://doi.org/10.1002/j.1538-7305.1948.tb01338.x

[13] Wang, T. C. \& Lee, H. D. (2009). Developing a fuzzy TOPSIS approach based on subjective weights and objective weights. Expert Systems with Applications, 36, 8980-8985. https://doi.org/10.1016/j.eswa.2008.11.035

[14] Lotfi, F. H. \& Fallahnejad, R. (2010). Imprecise Shannon's Entropy and Multi Attribute Decision Making. Entropy, 12, 53-62. https://doi.org/10.3390/e12010053

[15] Lin, Y., Chen, M. Y., \& Liu, S. (2004). Theory of grey systems: capturing uncertainties of grey information. Kybernetes, 33(2), 196-218. https://doi.org/10.1108/03684920410514139

[16] Liu, S. \& Lin, Y. (2006). Grey information: theory and practical applications. USA, Springer.

[17] Feng, C. M. \& Wang, R. T. (2000). Performance evaluation for airlines including the consideration of financial ratios. Journal of Air Transport Management, 6, 133-142. https://doi.org/10.1016/S0969-6997(00)00003-X

[18] Kuo, Y., Yang, T., \& Huang, G.-W. (2008). The use of grey relational analysis in solving multiple attribute decisionmaking problems. Computers \& Industrial Engineering, 55(1), 80-93. https://doi.org/10.1016/j.cie.2007.12.002

[19] Wen, K. L. (2004). Grey systems: modeling and prediction. Yang's Scientific Research Institute, USA.

[20] Tsai, C. H., Chang C. H., \& Chen, L. (2003). Applying grey relational analysis to the vendor evaluation model. International Journal of the Computer, the Internet and Management, 11(3), 45-53.

[21] Fung, C.-P. (2003). Manufacturing process optimization for wear property of fiber-reinforced polybutylene terephthalate composites with grey relational analysis. Wear, 254, 298306. https://doi.org/10.1016/S0043-1648(03)00013-9

[22] Phillips, S. J., Anderson, R. P., \& Schapire, R. E. (2006). Maximum entropy modelling of species geographic distributions. Ecological Modelling, 190(3), 231-259. https://doi.org/10.1016/j.ecolmodel.2005.03.026

[23] Özdağoğlu, A., Gümüş, Y., Özdağoğlu, G., \& Gümüş, G. K. (2017). Evaluating financial performance with grey relational analysis: an application of manufacturing companies listed on borsa Istanbul. The Journal of Accounting and Finance, 73, 289-312. https://doi.org/10.25095/mufad.396758 


\section{Contact information:}

Orkun ALPTEKIN, Asst. Professor Dr.

Eskişehir Osmangazi University, Faculty of Engineering and Architecture,

Department of Architecture

Bademlik Campus, 26480, Eskişehir, Turkey

E-mail: orkunalptekin@outlook.com

Nesrin ALPTEKIN, Professor Dr.

Anadolu University, Faculty of Business Administration

Yunusemre Campus, 26470, Eskişehir, Turkey

E-mail: nesrinesen@anadolu.edu.tr

Bilal SARAÇ, Research Asst.

Anadolu University, Faculty of Business Administration

Yunusemre Campus, 26470, Eskişehir, Turkey

E-mail: b_sarac@anadolu.edu.tr 